\title{
Vibriosis in Cultured Seahorse(Hippocampus spp.) in Khanh Hoa Province, Vietnam
}

\author{
Dang Thuy Binh ${ }^{1 *}$, Vu Dang Ha Quyen ${ }^{1}$, Tran Quang Sang ${ }^{1}$, Truong Thi Oanh ${ }^{1}$ \\ ${ }^{(1)}$ Institute for Biotechnology and Environment, Nha Trang University \\ 02 Nguyen Dinh Chieu Street. Nha Trang City, Vietnam \\ *binhdt@ntu.edu.vn
}

\begin{abstract}
Seahorse (Hippocampus spp) are economically valuable species, and are used in traditional medicine. In Vietnam, seahorse cultivation has been recently developed in some regions namely Khanh Hoa, Ninh Thuan, Hue, Da Nang and Vung Tau. Some seahorse farms in Khanh Hoa are now facing problems with unknown disease occuring in seahorses (Hippocampus spp.). In the present study, Vibrio bacteria were isolated from Hippocampus spp., which had ulcerations. Physiological and biochemical testing as well as 16S rDNA sequencing confirmed that the bacterium were closely related to Vibrio harveyi. V. alginolyticus, and V. vulnificus. Vibrio harveyi were grouped with V. campbellii, and other Vibrio sp. species, however, the luminescent ability would help to confirm species identification. Further studies need to be focused on optimal environmental parameters as well as prevention and treatment methods to better and sustainable seahorse farming.
\end{abstract}

Keywords: seahorse, bacteria, Vibrio, Hippocampus spp., Vietnam

Abbreviation: Vibriosis in cultured seahorse

\section{INTRODUCTION}

Seahorses (Hippocampus spp.) is a group of aquatic animals with high economic value, has long been used as folk medicine[1]. Every year, about 20 millions seahorses were collected from the wild[2] to be used for medical purposes [3], [4].

As valuable animals, seahorses recently became a cultivated species of number of nations in the world such as Australia (H. abdominalis), Srianka (H. kuda), Indonesia (H. kuda), Brazil (H. reidi), Mexico (H. erectus), Ireland (H. hippocampus) and New Zealand (H. abdominalis) [5]. In Vietnam,seahorse aquaculture is developing in the Southern and South Central provinces such as Hue, Da Nang, Khanh Hoa, Ninh Thuan, and Vung Tau. Currently, among 7 species distributed in local waters, three species (H. kuda, H. comes and $H$. histrix) have been found to possess a closed life cycle, attaining a maturesize after seven to ten months age [6]. H. spinosissimus, H. trimaculatus and H. kelloggi have also been the subject of genetic conservation program in Vietnam.

One of the major challenges for seahorse farming is the resistance of these animals are relatively weak. Seahorses are very susceptible to infection by pathogen such as parasites, bacteria and fungi [7]. In particular, bacterial diseases occur throughout the year, and cause the biggest damage [8], [9].

Vibrio are bacteria that often appear on aquatic animals. Some Vibrio species are pathogens on marine fish species such as Vibrio anguillarum, V. ordalii, V. harveyi, V. splendida, V. orientalis, V. fischeri. There have been several studies reported Vibrio that causes disease in seahorse, the first signs are anorexia, lethargy swim, pale tail and fin, white patch, deep skin ulcers [8], [10], [11], [12], [13].

In recent years, disease outbreak has been reported in some seahorse farms, and in conservative captive tanks in Khanh Hoa Province. Diseases seahorse often have the clinical sign of Vibriosis. The aim of this study is isolate and identify Vibrio bacteria in infected culture seahorses (Hippocampus spp.) at Khanh Hoa Province, Vietnam.

\section{MATERial AND Methods}

\subsection{Sampling and Localities}

Seahorse were kept at 120 lit-glass tanks (at Marine culture Research and Development Center (MRDC) at Song Lo), 500 lit-composit tanks (at Luong Son), and $2 \mathrm{~m}^{3}$-ciment tanks (at Ba Lang). 
Recirculated water system was applied for all systems. The environmental parameters (temparature, $\mathrm{pH}, \mathrm{PO}_{4}, \mathrm{NH}_{3}$, and $\mathrm{NO}_{2}$ ), and microbial commitee (total aerobic and total Vibrio bacteria) were analysed daily (temparature, $\mathrm{pH}$ ) and twice a month (for $\mathrm{PO}_{4}, \mathrm{NH}_{3}$, and $\mathrm{NO}_{2}$, and microbial parameters).

Disease seahorse species (Hippocampus kuda $(n=40)$, H. spinosissimus $(n=5), H$. comes $(n=30)$ ) were colected from captive tanks in the hatchery at Song Lo, Luong Son, and Ba Lang (Khanh Hoa Province, Vietnam) from 2013-2014.The common clinical signs such as lethargic swim, pale and amputed tail, pale and deep skin ulcer (Fig.1).
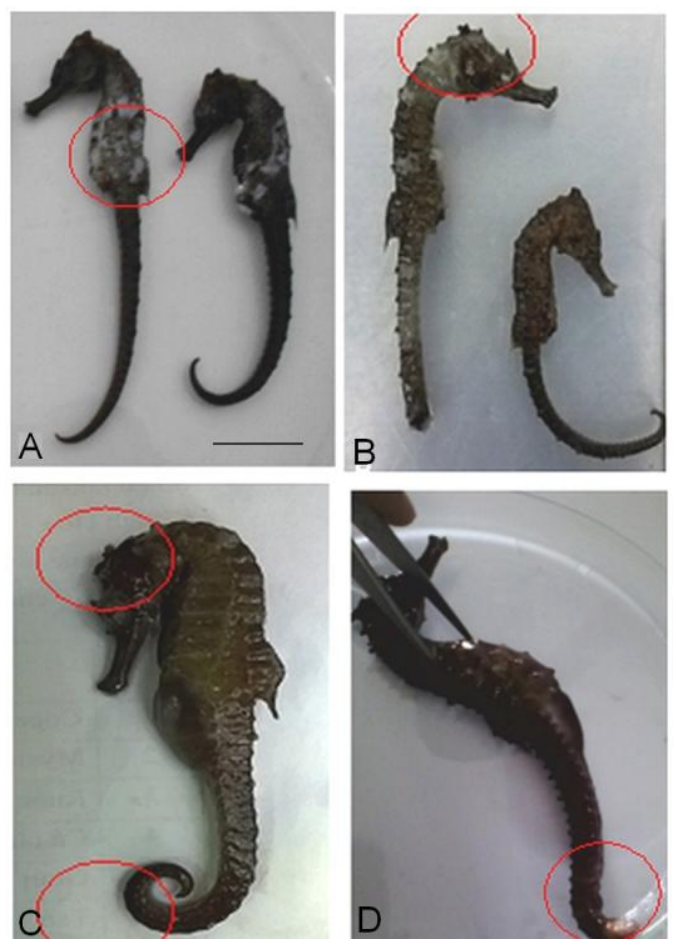

Fig1. Disease seahorse with vibriosis clinical symptom (A,B:Hippocampus kuda, C. H. comes; D: H. spinosissimus). Red circle showed the damage sites. Scale bar: $1 \mathrm{~mm}$ for $A, B, C$, and $2 \mathrm{~mm}$ for $D$

\subsection{Vibrio Isolation}

Vibrio bacteria were isolated from skin ulcer and kidney of infected seahorses in TCBS (Thiosulphate Bilesalt Citrate Sucrose) Agar, NA (Nutrient Agar) supplemented with 3\% $\mathrm{NaCl}$ and Marine Agar (MA) according to Raj et al. (2010)[14] and Tendencia (2004)[15]. The bacteria were cultured at $28^{\circ} \mathrm{C}$ for $24 \pm 2$ hours. The different colonies on TCBS plate, and luminescent colonies on NA or MA culture media will be purified and checked the morphological, biochemical, and physiological characteristics.

\subsection{Morphological, biochemical, and physiological characteristics of isolated Vibrio}

Morphological, biochemical, and physiological characteristics have been selected to identify Vibrio bacteria (Tab. 2) based on diagnostic criteria of pathogenic Vibrio in seafood [16]. The shape of bacteria is determined by Gram staining methods [17]. Mobility of bacteria were checked using soft agar containing $0.5 \%$ agar supplemented with Triphenyltetrazolium chloride (TTC) ; the possibility of development of bacteria in different $\mathrm{NaCl}$ concentrations $(0 \%, 1 \%, 3 \%, 6 \%, 8 \%, 10 \%)$ were also examined. API-20E, and API-20NE Kit (Biomerieux, France) were applied to determine biochemical characteristics. Combined physiological, and biochemical characters were submited to Analytical Profile Index on the API website (http://www.tgw1916.net/bacteria_logare.html).

\subsection{Molecular Identification}

Bacterial DNA was extracted by Chelex (Biorad, USA) according to manufacturer's procedures. 16S rDNA gene fragment of bacteria were amplified by PCR using primers: 27 F (5'AGATTTGATCCTGGCTCAG3') and the 1492 R (5'GGTTACCTTGTTACGACTT3') [18]. PCR was carried out with a total volume of $25 \mu 1$ with components as follows: Buffer 10x $(2,5 \mu 1)$, DNA (2$20 \mathrm{ng})$, each primer $(0,1 \mu \mathrm{M})$, dNTP $(0.1 \mathrm{~mm}$ each), Taq Polymerase $(1,25 \mathrm{U})$. Temperature cycle of 
reaction: $94^{\circ} \mathrm{C}$ for 7 minutes; 30 cycles for the period $94^{\circ} \mathrm{C}$ for 30 seconds, $50{ }^{\circ} \mathrm{C}$ for 30 seconds, 72 ${ }^{\circ} \mathrm{C}$ for 1 minute; extent at $72{ }^{\circ} \mathrm{C}$ for 7 minutes. Obtained $16 \mathrm{~S}$ gene sequencing results were aligned by Sequencher 4.1.4. Results were compared with GenBank sequences using BLAST (www.ncbi.nlm.nih.gov/blast/).

\subsection{Phylogenetic Analysis}

Four sequences in this study together with nine sequences of other Vibrio species available from Genbank were used in the phylogenetic analysis. Data were analysed using three approaches, i.e., Neighbour Joining (NJ), Maximum Parsimony (MP) and Bayesian Inference (BI). NJ analyses were conducted from MEGA 6 under 1000 replicates. MP analysis were conducted using PAUP* 4.0[19]. Bootstrap support values of the MP analysis were used to assess the robustness of the findings. Bootstrap support values were computed from 1,000 replicates randomized 10 times with treebisection-reconnection (TBR) addition sequence.

Prior to BI analyses, best-fit models of nucleotide substitution were selected by the Akalike Information Criterion as implemented by and MrModeltest 2.2 [20]. Bayesian analyses were conducted in MrBayes 3.1.2 under the selected best-fit models and parameters. Numbers at the interior branches of the majority-rule consensus tree present posterior probability (PP). Tree display and editing were performed in TreeView 1.6.6 [21].

\section{RESULT AND DISCUSSION}

\subsection{Seahorse Disease Status}

Moribund juvenile and adult seahorses (Hippocampus kuda $(4.96 \pm 0.05 \mathrm{~mm}, \mathrm{n}=40), H$. spinosisimus $(11.1 \pm 1.25 \mathrm{~mm}, \mathrm{n}=5), H$. comes $(5.38 \mathrm{~mm} \pm 0.45, \mathrm{n}=30)$ were collected at captive tanks in MRDC at Song Lo, and hatcheries at Luong Son, and Ba Lang, Nha Trang City, Khanh Hoa Province, Vietnam. The infected seahorse showed external lesions at the abdoment, head, and tail. Sometimes, tail was turning white, haemorrhages with rot (Fig.1). In general, diseases appear scattered throughout the year, however, the outbreak occurs mainly in the months of the rainy season (October to December) when the temperature changes suddenly.

Table 1. Environmental and microbial parameters in the seahorse tanks

\begin{tabular}{|l|l|l|l|l|l|l|l|l|l|l|}
\hline & \multicolumn{5}{|c|}{ Heathy seahorse } & \multicolumn{7}{c|}{ Disease seahorse } \\
\cline { 2 - 12 } Time & $\begin{array}{l}\text { Total } \\
\text { aerobic } \\
\text { Bacteria } \\
(\mathrm{CFU} / \mathrm{ml})\end{array}$ & $\begin{array}{l}\text { Total } \\
\text { Vibrio } \\
(\mathrm{CFU} / \mathrm{ml})\end{array}$ & $\begin{array}{l}\mathrm{NH}_{3} \\
(\mathrm{mg} / \mathrm{l})\end{array}$ & $\begin{array}{l}\mathrm{NO}_{2}^{-} \\
(\mathrm{mg} / \mathrm{l})\end{array}$ & $\begin{array}{l}\mathrm{PO}_{4}^{-} \\
(\mathrm{mg} / \mathrm{l})\end{array}$ & $\begin{array}{l}\text { Total } \\
\text { aerobic } \\
\text { Bacteria } \\
(\mathrm{CFU} / \mathrm{ml})\end{array}$ & $\begin{array}{l}\text { Total } \\
\text { Vibrio } \\
(\mathrm{CFU} / \mathrm{ml})\end{array}$ & $\begin{array}{l}\mathrm{NH}_{3} \\
(\mathrm{mg} / \mathrm{l})\end{array}$ & $\begin{array}{l}\mathrm{NO}_{2}^{-} \\
(\mathrm{mg} / \mathrm{l})\end{array}$ & $\begin{array}{l}\mathrm{PO}_{4}{ }^{-} \\
(\mathrm{mg} / \mathrm{l})\end{array}$ \\
\hline $4 / 2013$ & $1.5 \times 10^{3}$ & $1.0 \times 10^{2}$ & 0.1 & 0.05 & 0.05 & $5,2 \times 10^{3}$ & $3.0 \times 10^{3}$ & $\mathbf{0 . 5}$ & $>\mathbf{5}$ & $\mathbf{1}$ \\
\hline $7 / 2013$ & $1.8 \times 10^{3}$ & $1.2 \times 10^{2}$ & 0.1 & 0.05 & 0.05 & $6.0 \times 10^{3}$ & $2.0 \times 10^{3}$ & $<0,5$ & 0,1 & $>1$ \\
\hline $8 / 2013$ & $1.8 \times 10^{3}$ & $1.0 \times 10^{2}$ & 0.15 & 0.05 & 0.05 & $4.8 \times 10^{3}$ & $3.5 \times 10^{3}$ & 0,5 & $0,5<1$ & 1 \\
\hline $10 / 2013$ & $1.8 \times 10^{3}$ & $1.0 \times 10^{2}$ & 0.1 & 0.05 & 0.05 & $5.3 \times 10^{3}$ & $4.2 \times 10^{3}$ & 1 & $>1$ & 1 \\
\hline $12 / 2013$ & $1.5 \times 10^{3}$ & $1.0 \times 10^{2}$ & 0.12 & 0.1 & 0.15 & $\mathbf{9 . 0 \times 1 0 ^ { 3 }}$ & $\mathbf{3 . 6 \times 1 0 ^ { 3 }}$ & 0.5 & 0.5 & 0.5 \\
\hline $3 / 2014$ & $1.3 \times 10^{3}$ & $1,1 \times 10^{2}$ & 0.1 & 0.25 & 0.5 & & & & & \\
\hline $4 / 2014$ & & & & & & $8 \times 10^{3}$ & $4 \times 10^{3}$ & 0.1 & 0.5 & 1 \\
\hline $7 / 2014$ & $1.5 \times 10^{3}$ & $1,2 \times 10^{2}$ & 0,1 & 0.25 & 0,5 & & & & & \\
\hline $8 / 2014$ & $1.6 \times 10^{3}$ & $1,0 \times 10^{2}$ & 0.1 & 0.25 & 0.5 & & & & & \\
\hline $10 / 2014$ & $1.5 \times 10^{3}$ & $1,2 \times 10^{2}$ & & & & $4 \times 10^{3}$ & $2 \times 10^{3}$ & 0,25 & 0,5 & 1 \\
\hline $11 / 2014$ & $1.5 \times 10^{3}$ & $1,2 \times 10^{2}$ & 0.1 & 0.25 & 0.5 & & & & & \\
\hline $12 / 2014$ & $1.2 \times 10^{3}$ & $1,0 \times 10^{2}$ & & & & $1,0 \times 10^{4}$ & $3 \times 10^{3}$ & 0.5 & 5 & $0, .5$ \\
\hline
\end{tabular}

Following culture periods, disease occured throuthout the year 2013, and three times (on April, July, and December) in year 2014. The marked differences in the environmental parameters, and bacteria have been reported (Tab.1). In the tank with healthy seahorse, environmental and microbial parameters is within the limits allowed for the aquaculture $\left(\mathrm{PO}_{4}<0,1 \mathrm{mg} / \mathrm{l}, \mathrm{NO}_{2}<0,1 \mathrm{mg} / \mathrm{l}, \mathrm{NH}_{3} / \mathrm{NH}_{4}=\right.$ $0,1 \div 0,2 \mathrm{mg} / \mathrm{l})$. In contrast, all parameters in diseased tanks showed higher concentration, and extending the limitation, especially on April 2013 and December 2014, the $\mathrm{NO}_{2}$ is over 5mg/l, and $\mathrm{PO}_{4}$ reach $1 \mathrm{mg} / \mathrm{l}$. Aditionally, total aerobic, and total Vibrio were also higher when compared between healthy and diseased seahorse tanks. The higest number was observed on December, 2013 (total 
aerobic $9.0 \times 10^{3}$ and total Vibrio $\left.3.6 \times 10^{3}\right)$, and December, $2014\left(1.0 \times 10^{4}\right.$ and $3.0 \times 10^{4}$, respectively).

\subsection{Bacterial Isolation}

In the year 2013, the outbreak occured in $H$. kuda and H. spinosissimus. In total, 56 isolates were cultured and characterized morphologically. Among that 50 found on $H$. kuda $(\mathrm{n}=30)$, and the isolate (V1) was dominated with colonies are green, round, smooth on TCBS, diameter of $2-2.5 \mathrm{~mm}$ after 18 - 24 h incubation; luminescent on TCBS. Six isolates were detected on H. spinosissimus $(\mathrm{n}=5)$ of the colonies are yellow, round and smooth. In 2014, 18 isolates (yelow, round, smooth) were found on H. comes $(\mathrm{n}=30)$, and 12 isolates (green, round, smooth) were detected on H. kuda $(\mathrm{n}=10)$.

\subsection{Biochemical Characterization of Bacterial Isolates}

Table 2: Morphological, biochemical and physiological characteristics of Vibrio spp. strains

\begin{tabular}{|c|c|c|c|c|}
\hline Biochemical test & $\begin{array}{l}\text { Vibrio vulnificus } \\
\text { (Strain V9) }\end{array}$ & $\begin{array}{l}\text { Vibrio } \\
\text { harveyi } \\
\text { (Strain V1) }\end{array}$ & $\begin{array}{l}\text { Vibrio } \\
\text { alginolyticus } \\
\text { (Strain V5 and } \\
\text { V22) }\end{array}$ & $\begin{array}{l}\text { Vibrio } \\
\text { alginolyticus } \\
\text { (Strain V2) }\end{array}$ \\
\hline Infected species & H. comes & H. kuda & H. kuda & H. spiosissimus \\
\hline Growth on TCBS & $\mathbf{G}$ & $\mathbf{G}$ & $\mathbf{Y}$ & $\mathbf{Y}$ \\
\hline OX (oxidase test) & - & + & + & + \\
\hline $\mathbf{0 1 2 9}((0.5 \mu \mathrm{g})$ & $\mathrm{S}$ & $\mathrm{S}$ & S & $\mathrm{S}$ \\
\hline VP(Voges-Proskauer) & - & - & - & - \\
\hline Indole & + & + & + & + \\
\hline Luminescence & - & + & - & - \\
\hline URE (urea) & - & - & - & - \\
\hline $\begin{array}{l}\text { OPNG(p-nitrophenyl- } \beta \text { - } \\
\text { Dgalactopyranoside) }\end{array}$ & + & - & - & - \\
\hline LDC (Lysine decarboxylase) & + & - & + & + \\
\hline ODC (Ornithine decarboxylase) & + & - & + & + \\
\hline$\underline{\underline{\text { ADH }} \text { (arginine) }}$ & + & - & - & - \\
\hline$\overline{\text { TRP }}$ (tryptophane) & + & + & + & + \\
\hline GLU (glucose) & + & + & + & + \\
\hline$\overline{\text { ESC (esculin) }}$ & - & - & - & - \\
\hline Sucrose & - & - & + & + \\
\hline GEL (gelatine) & - & + & $+/-$ & + \\
\hline ARA (arabinose) & - & - & - & - \\
\hline$\overline{\text { MNE (mannose) }}$ & - & + & + & + \\
\hline MAN (mannitol) & - & + & + & + \\
\hline NAG (N-acetyl-glucosamine) & - & - & - & - \\
\hline MAL (maltose) & - & + & - & - \\
\hline$\overline{\text { GNT (gluconate) }}$ & - & + & $+/-$ & \\
\hline Lactose & + & - & - & - \\
\hline Sorbitol & - & - & - & - \\
\hline$\underline{\text { CAP } \text { (caprate) }}$ & + & + & - & $\mathrm{A}$ \\
\hline$\overline{\overline{\text { ADI }} \text { (adipate) }}$ & - & - & - & - \\
\hline MLT (malate) & - & - & + & + \\
\hline$\overline{\text { CIT (citrate) }}$ & + & - & - & + \\
\hline$\overline{\mathbf{P A C}}$ (phenyl-acetate) & - & - & - & - \\
\hline$\overline{\mathbf{N O}_{3}}$ (Potassium nitrate) & + & + & + & + \\
\hline \multicolumn{5}{|l|}{ Growth at percentage $\mathrm{NaCl}$} \\
\hline $0 \% \mathrm{NaCl}$ & - & - & - & - \\
\hline $3 \% \mathrm{NaCl}$ & + & + & + & + \\
\hline $6 \% \mathrm{NaCl}$ & + & + & + & + \\
\hline $8 \% \mathrm{NaCl}$ & - & - & - & - \\
\hline $10 \% \mathrm{NaCl}$ & - & - & - & - \\
\hline
\end{tabular}

Among collected isolates, five isolates were selected based on high frequency in diference seahorse species. All isolates were Gram-negative rods, motile, oxidase- and catalase-positive, sensitive to the vibriostatic agent $\mathrm{O} 129$ at $0.5 \mu \mathrm{g}$ and fermentative, Glucose oxidase, indole are positive; not ferment lactose, non produce $\mathrm{H} 2 \mathrm{~S}$; developed in $3 \%$ and $6 \%$ salt concentration, not grow in $0 \%, 8 \%$ (Tab. 2). 
Based on the API 20E and API 20NE (BioMetrieux, S.A. France) strips, the isolates were characterized by the database APILAB Plus supplied by the manufacturer.The coming result as follow: Vibrio vulnificus (strain V9), with a probability of $96 \%$ in $\mathrm{H}$. comes; 2 high frequency strains (V. alginolyticus -V5 and V22), and V. harveyi-V1)) were detected on $H$. kuda (probability of $98.8 \%$ and 95\%), while $V$. alginolyticus-V2 (probability of 95\%) was found on $H$. spinosissimus (Fig. 2).Among isolates, only $V$. harveyi, exhibited luminescence on NA media.

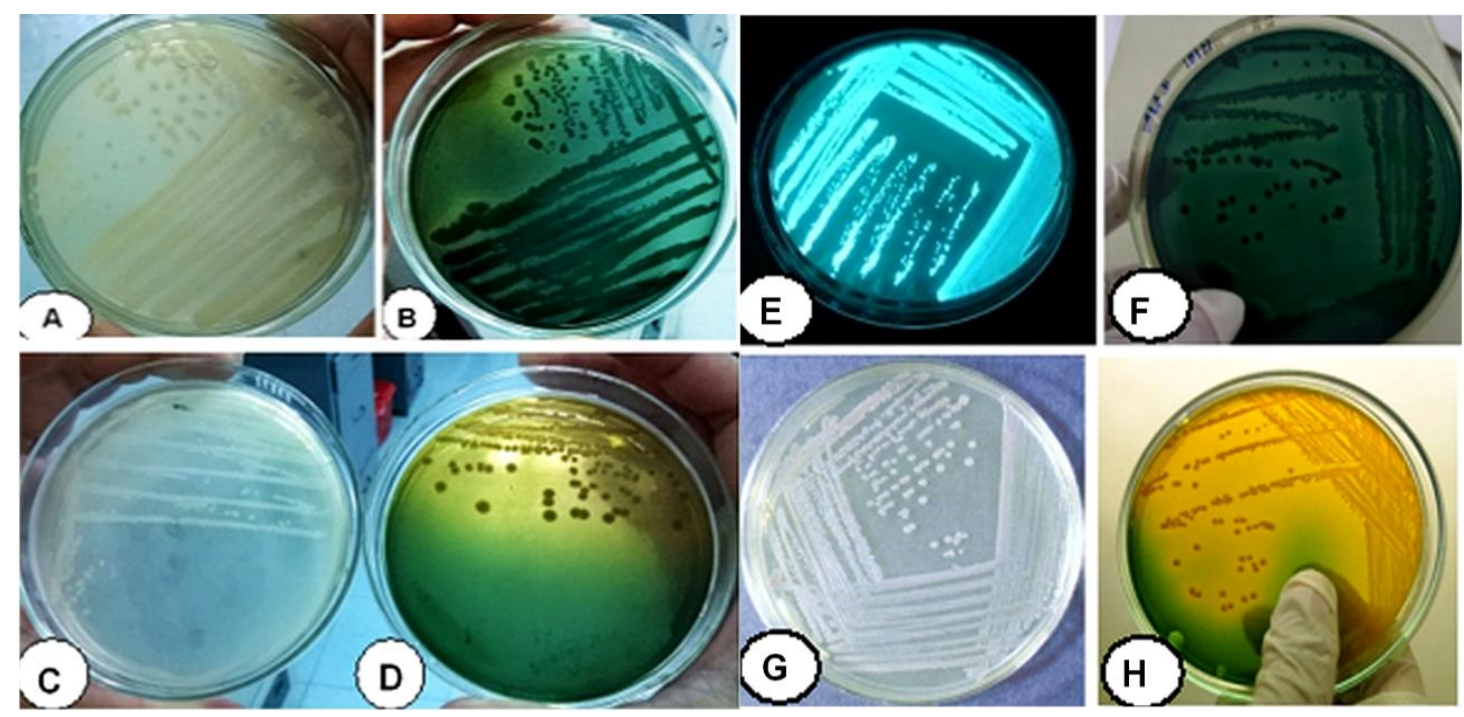

Fig2. Vibrio spp . colonies on Nutrient and TCBS agar. (A,B : V. vulnificus on Hippocaampus comes; $C, D: V$. alginolyticus on H. kuda; E,F : V. harveyi on H. kuda (Luminescence on NA), and G,H : V. alginolyticus on $H$. spinosissimus.

\subsection{Molecular Identification by 16S Ribosomal DNA (16S rDNA)}

The obtained 16S rRNA sequences were comparared to the sequences of pathogenic bacteria in the GenBank. Strain V1 shows similarities to strains of Vibrio harveyi, V. campbelli, and Vibrio sp. (Max ident $=100 \%$; E value $=0$; Query cover $=100 \%$ ). Strain V2, V5 and V22 exhibit highly identical to $V$. alginolyticus (Max ident $=99.6 \%$, and $99.5 \%$, respectively), while V9 is matched with $V$. vulnificus (Max ident $=97 \%$ ).

Vibrio spp. species are highly polymorphic, identification systems are complex. Using biochemical characteristics, it is difficult to accurately identify to the species level, particularly for $V$. harveyi, and closed related species[22]. 16S rRNA genes and other genetic housekeeping is widely used in the identification of Vibrio[23]. But the study of WIIK et al. (1995)[23] showed that the 16S rRNA does not identify all the different species of Vibrio.

\subsection{Phylogenetic Analysis}

The 16S rRNA dataset consists of more than $1400 \mathrm{bp}$, of which $1326 \mathrm{bp}$ were unambiguously aligned. Tree topology from the MP method was similar to that of the best NJ tree and the BI tree. The phylogenetic tree was divided into four main groups with high BT supports (Fig. 3).

Vibrio harveyi isolate from $H$. kuda was clustered with V. harveyi, V. campbelli, and Vibrio sp. available on Genbank. The two isolates of $V$. alginolytticus from $H$. kuda and $H$. spinosissimus were sister species to $V$. alginolytitcus (Accession number DQ173157), and $V$. vulnificus from H. comes was also group with the same species (Accession number HM996972). V. parahaemolyticus was distinct from all current species.

16S rRNA sequences gave a better resolution for $V$. alginolyticus and $V$. vulnificus. However, this sequences can not used to distinguish between $V$. harveyi, and $V$. campbelli. The combination of biochemical characteristics, and molecular markers may help to acurately species identification. With the capable of luminescent of current isolates from $H$. kuda, it may be tentative identify as $V$. harveyi. Other molecular makers such as toxic genes should be used for further identification.

There also some of Vibrio species have been reported as causative agents on seahorse disease. $V$. alginolyticus cause necrotic foci in different organs (kidney, liver, heart) on Hippocampus reidi in Brazil [24], $V$. harveyi has been reported of skin haemorrhages and white patch disease in Hippocampus sp., in India [14], H. kuda in Spain [8] and the Philippines [15], Vibrio spp. are also known to cause deep skin ulcers and lesionson $H$. kuda as well [25][26]. 


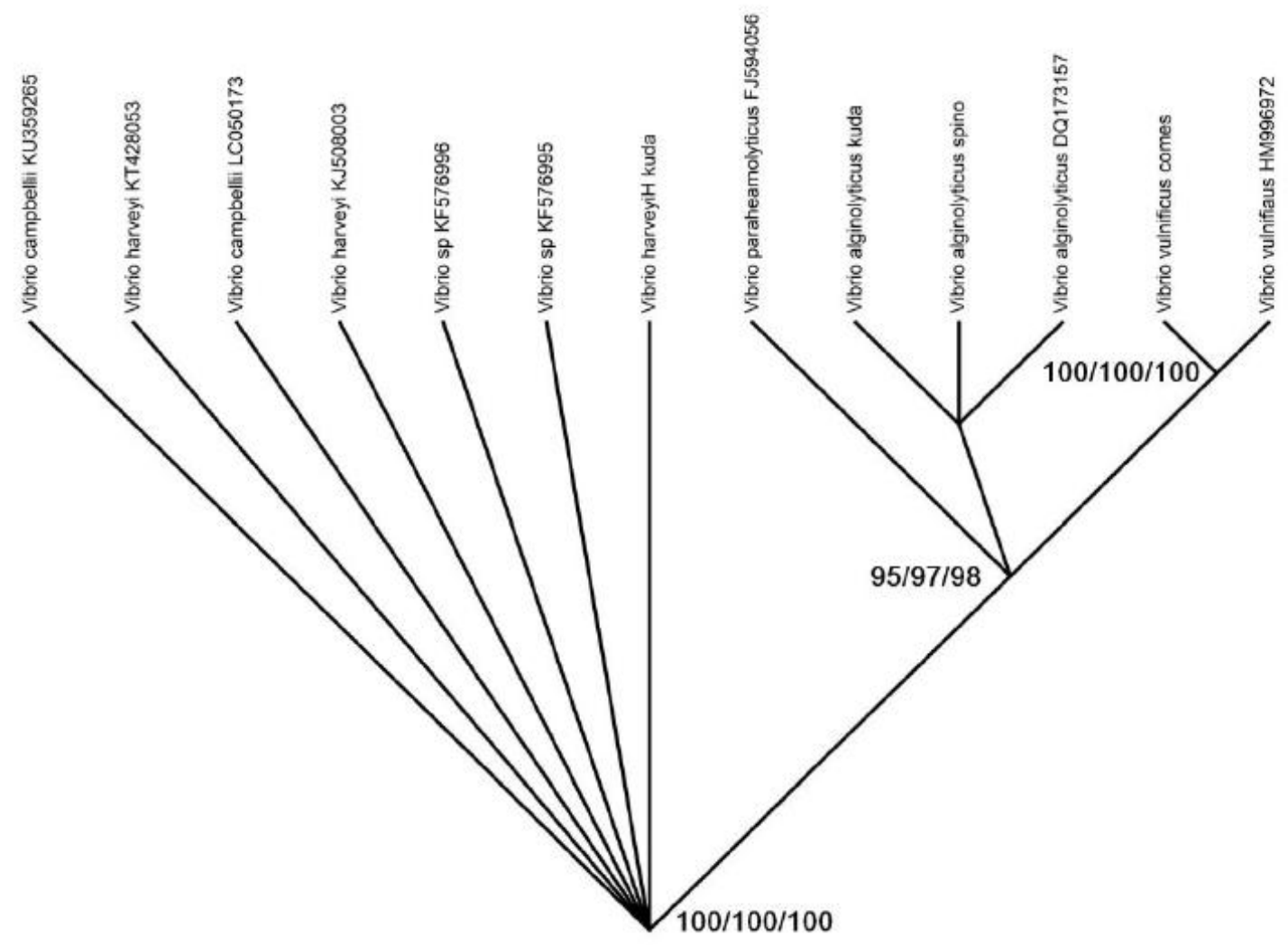

Fig 3. Phylogenetic relationships of Virbrio species based on $16 S$ rRNA. Bootstrap value from NJ, MP and BI analysis along the branch

Although life cycle was completed for at least 5 species of seahorses in Vietnam, seahorse aquaculture face unique challenges for health care due to Vibriosis. The best way to manage disease is through prevention such as optimal environmental parameters, and good diet to reduce health problems[25].

At the rule of CITES of F2 seahorse broodstock for exportation, seahorse culture in Vietnam is getting down recently. As broodstock is mainly collected from the wild, plus food are also wild mysis, and copepods, seahorse may got Vibrio diseases through bad transportation and/or from a food sources. Tendencia (2004) [15] also reported food of seahorses (the group Ascetes spp.) in the Philippines contain large luminous bacteria.

This is the first report on Vibrio infection on seahorse in Vietnam. Biochemical and molecular characteristics have shown the ability to detect the pathogens and their phylogenetic relationships. Further studies are needed to establish the optimal environmental parameters, detecting threshold level of Vibrio spp. in the rearing water, as well as the effective prevention and treating methods for different Vibrio diseases on particular seahorse species.

\section{CONCLUSION}

The study results showed that the pathogen caused ulcer disease in seahorse (Hippocampus spp.) cultured in Vietnam are Vibrio spp. species. V. alginolyticus, V. harveyi, and V. vulnificus were detected based on morphological, physiological, biochemical, and molecular characteristis.There is a correlation between environmental parameters, microorganisms and disease occurrence.

\section{REFERENCES}

[1] Lourie S. A., Pritchard J. C., Casey S. P., Truong S .K., Hall H. J., The taxonomy of Vietnam's exploited seahorses (Family Syngnathidae),Biol. J. Linn. Soc. 66(2), pp. 231-256 (1999).

[2] Vincent A. C. J., The international trade in seahorses, 172 (1996).

[3] Ryu B.,Qian Z. J. and Kim S. K., Purification of a peptide from seahorse, that inhibits TPAinduced MMP, iNOS and COX-2 expression through MAPK and NF- $\kappa$ B activation, and induces human osteoblastic and chondrocytic differentiation, Chem. Biol. Interact., 184(3), pp. 413-422 (2010).

[4] Zhang N., Xu B., Mou C., Yang W., Wei J., Lu L., Zhu J., Du J., Wu X., Ye L., Fu Z., Lu Y., 
Lin J., Sun Z., Su J., Dong M., and Xu A., Molecular profile of the unique species of traditional Chinese medicine, Chinese seahorse (Hippocampus kuda Bleeker),FEBS Lett., 550(1-3), pp. 124-134 (2003).

[5] Foster S. J. and Vincent A. C. J., Life history and ecology of seahorses: implications for conservation and management,J. Fish Biol., 65(1), pp. 1-61 (2004).

[6] Trương Sĩ Kỳ, Kỹ thuật nuôi cá ngựa ở biển Việt Nam. Nhà xuất bản Nông nghiệp, Thành phố Hồ Chí Minh (2000).

[7] Vincent A. and Clifton-Hadley R., Parasitic infection of the seahorse (Hippocampus erectus) a case report,J. Wildl. Dis., 25(3), pp. 404-406 (1989).

[8] Alcaide E., Gil-Sanz C., Sanjuán E., Esteve D., Amaro C. and Silveira L., Vibrio harveyi causes disease in seahorse, Hippocampus sp.,J. Fish Dis., 24(5), pp. 311-313 (2001).

[9] Austin B. B. and Austin D. A., Bacterial fish pathogens: disease in farmed and wild fish. Ellis Horwood, 1993.

[10] Balcázar J. L., Planas M., and Pintado J., Novel Mycobacterium Species in Seahorses with Tail Rot,Emerg. Infect. Dis., 17(9), pp. 1770-1772 (2011).

[11] Bombardini C., Florio D., Fichtel L., and Fioravanti M. L., Principali patologie dei Syngnathidae in cattività The main disease of Syngnathidae in captivity,Ittiopatologia, 3, pp. 205-211 (2006).

[12] Koldewey H. J. and Martin-Smith K. M., A global review of seahorse aquaculture,Aquaculture, 302(3-4), pp. 131-152, (2010).

[13] Tendencia E. A., Vibrio harveyi isolated from cage-cultured seabass Lates calcarifer Bloch in the Philippines, Aquac. Res., 33(6), pp. 455-458 (2002).

[14] Raj S., Thampi L. A. P. and Chauhan G. S., Characterization and infectivity evaluation of Vibrio harveyi causing white patch disease among captive reared seahorses, Hippocampus kuda, 39, pp. 151-156 (2010).

[15] Tendencia E.A., The first report of Vibrio harveyi infection in the sea horse Hippocampus kuda Bleekers 1852 in the Philippines,Aquac. Res., 35(13), pp. 1292-1294 (2004).

[16] Larsen J. L.và Pedersen K., Diagnostic schemes for Vibrio species, 1999.

[17] Barrow G.I. và Feltham R.K.A., Cowan and Steel's Manual for the Identification of Medical Bacteria. Cambridge University Press, 1993.

[18] Weisburg W. G., Barns S. M., Pelletier D. A., and Lane D. J., 16S ribosomal DNA amplification for phylogenetic study, J. Bacteriol., 173(2), pp. 697-703, (1991).

[19] Swofford D., PAUP*. Phylogenetic Analysis Using Parsimony (*and other methods). Version 4. Sinauer Associates, Sunderland, Massachussets, 2002.

[20] Nylander J. A., MrModeltest v2. Program distributed by the author. Evolutionary Biology Centre, Uppsala University. 2004.

[21] Page R. D., TreeView: an application to display phylogenetic trees on personal computers,Bioinformatics/computer Appl. Biosci.,12(4), pp. 357-358 (1996).

[22] Chatterjee S. and Haldar S., Vibrio Related Diseases in Aquaculture and Development of Rapid and Accurate Identification Methods, J. Mar. Sci. Res. Dev., pp. 1-7 (2012).

[23] Wiik R., Stackebrandt E., Valle O., Daae F. L., Rødseth O. M. and Andersen K., Classification of fish-pathogenic vibrios based on comparative 16S rRNA analysis.,Int. J. Syst. Bacteriol., 45(3), pp. 421-8, (1995).

[24] Martins M. L., Mouriño J. L. P., Fezer G. F., Buglione N. C. C., Garcia P., Silva B. C., Jatobá A., Vieira F. N., Isolation and experimental infection with Vibrio alginolyticus in the sea horse, Hippocampus reidi Ginsburg, 1933 (Osteichthyes: Syngnathidae) in Brazil.,Braz. J. Biol., 70(1), pp. 205-209 (2010).

[25] Sanaye S. V, Pawar H. B., Murugan A., Sreepada R. A., Singh T., and Ansari Z. A., Diseases and parasites in cultured yellow seahorse , Hippocampus kuda ( Bleeker, 1852 ), 32(11), 2013.

[26] LePage V. and Lumsden J., A Study of Syngnathid Diseases and Investigation of Ulcerative Dermatitis,p. 128, (2012). 


\section{AUTHOR'S BIOGRAPHY}

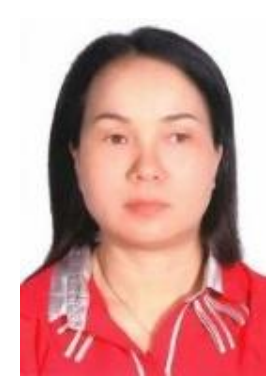

Dr. Binh Thuy Dang, has 15 years' experience working in molecular ecology applied to fisheries research. Dr. Binh is a senior researcher at the Institute for Biotechnology and Environment, Nha Trang University. Her research interests include biodiversity, population genetics and disease of aquatic organisms. Dr. Binh is a long time contributor and currently PI to the National Genetic resource conservation Project. Additionally, Dr. Binh also recently involved in several international project as PI, Co-PI, and task leader such as EU project: "Parasite Risk Assessment with Integrated Tools in EU fish production value chains", two USAID funding Peer Project "Conservation Genetics for Improved Biodiversity and Resource Management in a Changing Mekong Delta" and 'Building a Mekong River Genetic Biodiversity Research Network", as well as NORAD funded NORHED project" Incorporating Climate Change into Ecosystem Approaches to Fisheries and Aquaculture Management in Sri Lanka and Vietnam". 